and Thursday of each week from io to I 2 a.m., graduates may occupy themselves with a study of the clinical cases in the Hospital, and Museum demonstrations will be given under the direction of the Medical Superintendent and the Clinical Assistant. The following subjects will be studied: Enteric fever, undulant fever, phlebotomus fever, dengue fever, yellow fever, beriberi, pellagra, amœbic abscess, heatstroke, yaws, ulcerating granuloma, climatic bubo, filariasis, differential diagnosis of the fevers, \&c. The dates of the next course are from October 6 to October 24. Fee $£ 88 \mathrm{~s}$. payable to the Fellowship of Medicine. A syllabus of the course given from June 16 to July 4 can be forwarded on application.

\section{REVIEW S.}

A Textbook of Hyginne. By J. R. Currie, M.D.Glas., M.R.C.P.Edin., Professor of Public Health in the University of Glasgow. Edinburgh: E. and $S$. Livingstone. 1930. Pp. 844, with I Io illustrations. Price $27 \mathrm{~s}$.

This book is written for students of hygiene, and will be found an excellent textbook for candidates for the D.P.H. examinations.

The science of preventive medicine is growing so rapidly that there is a real need for a book which includes under one cover the present day methods of preventing disease, and the author is to be congratulated on having clearly fulfilled this purpose.

Dealing with air and ventilation, it is pointed out that the movement of air is the important factor. It takes a long time for the oxygen to decrease and the carbon dioxide to increase sufficiently to produce harm even in the most crowded room. The ill-effects are the result of heat and moisture, and the symptoms will be relieved by agitating the air by means of a fan.

Smoke may affect visibility for an area of fifty miles, and soot-collecting gauges show that in some towns over a ton of solid matter is deposited daily from smoke.
The chapters on sewage and river pollution are very interesting and are followed by one dealing with public health administration in Scotland and England and Wales. The functions of the various departments are clearly explained.

There is a very full chapter dealing with food. The value of different foods is first described from a physiological point of view, and the author then describes the various methods of preserving foods, and finally food poisoning. The law as applied both in England and Scotland is very clearly explained throughout the book.

Infectious and general diseases, vital statistics and climate are all fully described. Of special interest are the chapters on maternity, child welfare and school hygiene.

The book makes interesting reading and is very well produced. It should prove of great value to all students and practitioners of public health.

The Clinical Pathology of Thokacic Puncture Fluids. By S. Roodhouse Gloyne, M.D. D.P.H. John Bale, Sons and Danielsson, Ltd. Published I930. Pp. 83. Price ros. 6d.

As the author remarks in his preface, "a greater readiness to use an exploring syringe and the growing importance of operative treatment in chronic lung disease, tend steadily to increase the requests for the examination of thoracic puncture fluids."

He has succeeded in presenting in an an attractive readable form and in small compass all the essential facts regarding the technique of examination and includes several simple methods which require little equipment.

In discussing the interpretation of the results of examination, the views expressed founded as they are on long experience of laboratory work in a chest hospital, cannot fail to be of practical service to the clinician in extracting from the laboratory report any information of diagnostic value. The index is good and the illustrations instructive and well chosen. 